\title{
Onychomycosis: clinical, mycological and in vitro susceptibility testing of isolates of Trichophyton rubrum
}

\author{
Christiane Venske de Almeida Azambuja ${ }^{1}$ \\ Gabriel Baracy Klafke ${ }^{1}$
}

\author{
Luciana Alves Pimmel ${ }^{1}$ \\ Melissa Orzechowski Xavier ${ }^{1}$
}

DOI: $h$ ttp://dx.doi.org/10.1590/abd1806-4841.20142630

\begin{abstract}
BACKGROUND: Onychomycosis or nail fungal infection is the most common nail disease. Despite the wide range of studies on this condition, it remains difficult to establish the correct diagnosis and effective treatment. OвJECTIVES: To evaluate the efficacy of classical laboratory methods for the diagnosis of onychomycosis, and the in vitro susceptibility of the its main etiological agent to antifungals used in routine.

MeTHODS: Nail samples of 100 patients with clinically suspected feet onychomycosis were collected to confirm the diagnosis by direct mycological examination and fungal culture. In vitro antifungal susceptibility testing was performed against strains of the main dermatophyte isolated by microdilution, according to the standardized protocol (M38-A2 - CLSI)

RESULTS: Clinical diagnosis of onychomycosis was confirmed by laboratory analysis in $59 \%$ of patients. Of these, $54.2 \%$ were positive only in direct mycological examination, $44.1 \%$ in direct mycological examination and culture, and one case $(1.7 \%$ ) was positive only in culture, resulting in weak agreement between these tests (Kappa $=0.385 ; \mathrm{p}<0.001)$ High minimum inhibitory concentration values of fluconazole and itraconazole were observed in $66.7 \%$ and $25.0 \%$ of isolates of T. rubrum tested. Additionally, high MIC values of terbinafine and ciclopirox was detected in only one isolate, and this was one of the strains in which in vitro activity of itraconazole and fluconazole has not been proven.

CONCLUSIONS: Poor agreement was observed between direct mycological examination and culture for the diagnosis of onychomycosis, with direct mycological examination being significantly more sensitive. Except for fluconazole, the other three antifungals tested showed good in vitro activity against clinical isolates of T. rubrum. Keywords: Diagnostic tests, routine; Onychomycosis; Prevalence
\end{abstract}

\section{INTRODUCTION}

Onychomycosis is a nail infection caused by fungi, which may behave as primary pathogens invading the healthy nail plaque or develop secondarily to a preexisting nail disease. According to Haneke and to Zanardi et al., onychomycosis is the most common nail disease, accounting for nearly $30 \%$ of skin mycoses and from 18 to $40 \%$ of all nail conditions. ${ }^{1,2}$ When compared to other skin fungal infections, it is the most frequent and the most difficult to treat. ${ }^{3,4}$

Onychomycosis is considered an important public health problem, due to its high prevalence and therapeutic difficulty associated with high rates of recurrence and progression to chronic lesions. ${ }^{2,5,6}$ Other authors reinforce its relevance in clinical practi- ce because of its interference with patients' quality of life, leading to cosmetic impairment as well as to low self-esteem and functional capacity, even compromising work performance. ${ }^{6-11}$

Considering that it is not possible to confirm onychomycosis based only on clinical characteristics of the lesions and that etiologic agents have variable susceptibility to antifungal drugs, laboratory diagnosis is considered a necessary tool to establish disease etiology and help choose the best therapeutic option. ${ }^{2,12}$ However, although treatments for onychomycosis imply a high cost, collateral effects, and prolonged treatment time, in practice they are not used only when there is confirmed diagnosis, and negligent

\footnotetext{
Received on 18.03.2013.

Approved by the Advisory Board and accepted for publication on 30.06.2013.

Work conducted at the Mycology Laboratory of the School of Medicine of Universidade Federal do Rio Grande (FAMED-FURG) - Rio Grande (RS), Brazil. Conflict of interest: None

Financial funding: None

Universidade Federal do Rio Grande (FURG) - Rio Grande (RS), Brazil.
}

C2014 by Anais Brasileiros de Dermatologia 
patients usually do not see the doctor to receive appropriate guidance and treatments; in addition, empirical treatments are prescribed when there is only clinical suspicion but no laboratory confirmation of onychomycosis. ${ }^{13}$

In view of the foregoing, this study aimed to evaluate the efficacy of classical laboratory methods for the diagnosis of onychomycosis in patients with nail diseases suggestive of fungal nail involvement and the in vitro susceptibility of the main etiological agent of onychomycosis to antifungals used in routine care, with the purpose of contributing to a better diagnostic and therapeutic approach.

\section{MATERIAL AND METHODS}

A prospective cross-sectional study was conducted with 100 patients treated at a private dermatology clinic of Rio Grande, Southern Brazil, and at the Dermatology outpatient clinic of the University Hospital of Universidade Federal do Rio Grande (HUFURG) during a period of 18 months (January 2011 and June 2012).

The study was approved by the Research Ethics Committee of FURG (CEPAS no. 23116.002009/2011$14)$, and all patients who agreed to participate in the investigation signed a written consent form. The sample included patients who presented with changes in toenails compatible with onychomycosis, such as color change (yellowish or whitish nails), nail fragility, changes in nail thickness, and/or detached nail plate. The sample was selected by convenience. Exclusion criteria were: patients using topical and/or antifungal drugs at the time of sample collection or up to 15 days before the day of collection, individuals younger than 12 years old, and patients whose clinical samples were not enough for laboratory processing.

Patients underwent anamnesis and dermatological physical examination for collecting data on gender, age, skin color, time of lesion onset, previous antifungal treatment, clinical classification of onychomycosis type, number of affected nails, and presence of tinea pedis. Subsequently, clinical samples were collected by nail scraping after proper antisepsis with 70\% alcohol. The first debris collected was discarded, and fragments were obtained from the site closest to the transition between normal and affected nails areas. Samples were kept in sterile Petri dishes and processed in a mycology laboratory during a period of at least 48 hours.

Laboratory processing consisted of direct mycological examination (DME) and fungal culture. DME was performed by adding potassium hydroxide $(\mathrm{KOH}) 40 \%$ to nail fragments and scales with subsequent analysis by optical microscopy at 100-400x magnification. In this first evaluation, negative samples were stored overnight in a humid chamber and exami- ned again on the following day to confirm the result.

Fungal isolation was achieved by seeding duplicate samples and arranging nail fragments in Sabouraud dextrose agar added with chloramphenicol (SCL) and SCL agar added with cycloheximide. Cultures were incubated at a temperature of $25^{\circ} \mathrm{C}$ for up to 30 days with daily observations for checking fungal growth. The identification of the fungal genus/species was performed by observing both macroscopic (macromorfology) and micromorphologic aspects of isolated colonies, as well as by performing biochemical tests when needed.

Samples whose mycological culture revealed the growth of dermatophytes were considered positive, which confirmed the diagnosis of tinea unguium regardless of DME results. On the other hand, yeasts and nondermatophyte filamentous fungi (NDFF) isolated in cultures were considered etiologic agents only when DME results showed compatible structures, i.e., blastoconidia and tortuous septate hyaline hyphae, respectively.

In vitro antifungal susceptibility testing was performed against strains of the main dermatophyte isolated from clinical samples (Trichophyton rubrum) by duplicate microdilution, according to the protocol described by the Clinical and Laboratory Standards Institute (CLSI) 2002 guidelines, document M38-A2 for filamentous fungi. The following antifungals were tested: ciclopirox (32 to $0.0625 \mu \mathrm{g} / \mathrm{mL})$, terbinafine $(0.5$ to $0.0001 \mu \mathrm{g} / \mathrm{mL}$ ), fluconazole $(64$ to $0.125 \mu \mathrm{g} / \mathrm{mL})$, and itraconazole $(0.5$ to $0.0001 \mu \mathrm{g} / \mathrm{mL})$. The lowest antifungal concentration capable of inhibiting $80 \%$ of fungal growth was considered the minimum inhibitory concentration (MIC).

Descriptive analysis of data frequency was performed to investigate the association between variables of interest using the chi-square test for categorical variables and the t-test for quantitative variables. The Kappa coefficient was used to analyze the level of agreement between DME and mycologic culture. In all tests, the level of confidence was set at $5 \%$.

\section{RESULTS}

Of the 100 patients included in the study, 78 were women and 22 were men, and 74 were white. Mean age was 47 years old (standard deviation: 15.7 years) and $37 \%$ of patients were older than 50 years. Most patients came from the private clinic (85\%). Additionally, $67 \%$ reported to have been suffering with skin lesions for more than 1 year (during a period ranging from 13 months to more than 10 years) and $61 \%$ of all cases had a history of antifungal treatment. Thirty patients presented with tinea pedis, and half of the patients had up to two nails affected by onychomycosis, $24 \%$ had between three and five nails 
affected, and the remaining $26 \%$ had more than five nails affected (from six to ten).

Clinical diagnosis of onychomycosis was confirmed by laboratory analysis in 59 of patients (59\%), with mean age of 48 years $(p=0.700)$. Among these 59 cases, $24(40.7 \%)$ were aged above 50 years, $43(72.9 \%)$ were female, $16(27.1 \%)$ were male $(p=0.273)$, and 44 $(74.6 \%)$ reported that lesion onset occurred more than a year before.

Of the 59 confirmed cases, $32(54.2 \%)$ were positive only in DME, 26 (44.1\%) in DME and culture, and one case $(1.7 \%)$ was positive only in culture, which resulted in a weak agreement between DME and mycologic culture (Kappa $=0.385 ; p<0.001)$ (Table 1). Clinically, $44.1 \%(n=26)$ of the confirmed cases of onychomycosis were characterized by distal lateral subungueal onychomycosis (DLSO), $25.4 \%(n=15)$ by total onichodystrophy, $5.1 \%(\mathrm{n}=03)$ by superficial white onychomycosis, and $25.4 \%(\mathrm{n}=15)$ by a mixed pattern (presence of total onichodystrophy associated with DLSO or another pattern described) $(p=0.235)$. DME revealed the presence of regular septate hyaline hyphae in 50 patients, of tortuous septate hyaline hyphae in other five cases, and of oval and single-budding blastoconidea in three patients.

TABLE 1: Diagnosis of onychomycosis using direct mycological examination (DME) and mycological culture in clinical samples of patients with toenail diseases

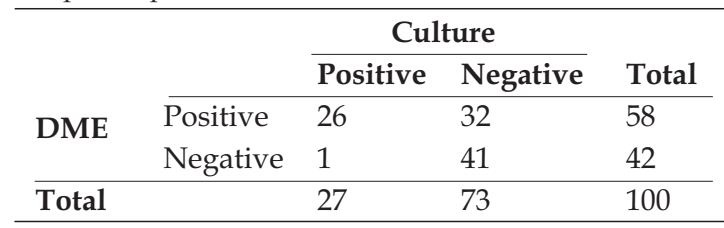

Mycologic culture allowed reaching a definite diagnosis of tinea unguium in 19 cases, 17 of which caused by T. rubrum and two by E. floccosum. In three cases, yeasts of the genus Candida were isolated from clinical samples, and the diagnosis of onychomycosis for this agent was considered due to the association between fungal isolation and the presence of blastoconidea in DME. Furthermore, other 10 cases with positive culture showed the growth of NDFF as belonging to genera Fusarium $(\mathrm{n}=4)$, Aspergillus $(\mathrm{n}=5)$, and Acremonium $(\mathrm{n}=1)$. Of these 10 patients, in only five the isolated NDFF (Fusarium sp. [n=4] and Aspergillus niger $[\mathrm{n}=1]$ ) was considered the causative agent of nail lesion, due to its association with DME showing the presence of tortuous hyaline hyphae. In the other five patients with negative DME, the NDFF isolated by culture was considered be concomitant and have no clinical implication. The case confirmed only by culture, whose DME result was negative, was caused by T. rubrum.

Laboratory diagnosis of onychomycosis occurred in $86.7 \%(26 / 30)$ of patients with associated tinea pedis infection $(p<0.001)$. The two cases of onychomycosis by E. floccosum presented with associated tinea pedis, which was also found in $47.1 \%(8 / 17)$ of patients with tinea unguium by T. rubrum.

Of the 12 T. rubrum isolates tested in vitro, $66.7 \%$ showed high MIC values for fluconazole (MIC $>4.0 \mu \mathrm{g} /$ $\mathrm{mL}$ ), $25 \%$ for itraconazole (MIC $\geq 0.25 \mu \mathrm{g} / \mathrm{mL}$ ), and only one isolate $(8.3 \%)$ had MIC $>1.0 \mu \mathrm{g} / \mathrm{mL}$ for ciclopirox and MIC $>0.5 \mu \mathrm{g} / \mathrm{mL}$ for terbinafine (Table 2). $\mathrm{MIC}_{50}$ and $\mathrm{MIC}_{90}$ of fluconazole were $16 \mu \mathrm{g} / \mathrm{mL}$ and $64 \mu \mathrm{g} / \mathrm{mL}$; of itraconazole, $0.125 \mu \mathrm{g} / \mathrm{mL}$ and $0.25 \mu \mathrm{g} / \mathrm{mL}$; of ciclopirox, $0.5 \mu \mathrm{g} / \mathrm{mL}$ and $1.0 \mu \mathrm{g} / \mathrm{mL}$; and of terbinafine, $0.0625 \mu \mathrm{g} / \mathrm{mL}$ and $0.125 \mu \mathrm{g} / \mathrm{mL}$, respectively.

TABLE 2: Results of microdilution tests for the evaluation of the in vitro activity of four antifungals against 12 clinical isolates of T. rubrum coming from cases of onychomycosis

\begin{tabular}{lllll}
\hline Clinical isolate & Itraconazole (MIC) & Fluconazole (MIC) & Terbinafine (MIC) & Cyclopirox \\
\hline 1 & $0.0625 \mu \mathrm{g} / \mathrm{mL}$ & $1 \mu \mathrm{g} / \mathrm{mL}$ & $0.0078 \mu \mathrm{g} / \mathrm{mL}$ & $0.5 \mu \mathrm{g} / \mathrm{mL}$ \\
2 & $0.0625 \mu \mathrm{g} / \mathrm{mL}$ & $2 \mu \mathrm{g} / \mathrm{mL}$ & $0.0313 \mu \mathrm{g} / \mathrm{mL}$ & $0.5 \mu \mathrm{g} / \mathrm{mL}$ \\
3 & $0.0625 \mu \mathrm{g} / \mathrm{mL}$ & $1 \mu \mathrm{g} / \mathrm{mL}$ & $0.125 \mu \mathrm{g} / \mathrm{mL}$ & $0.5 \mu \mathrm{g} / \mathrm{mL}$ \\
4 & $0.0625 \mu \mathrm{g} / \mathrm{mL}$ & $>64 \mu \mathrm{g} / \mathrm{mL}$ & $0.0313 \mu \mathrm{g} / \mathrm{mL}$ & $1 \mu \mathrm{g} / \mathrm{mL}$ \\
5 & $0.125 \mu \mathrm{g} / \mathrm{mL}$ & $2 \mu \mathrm{g} / \mathrm{mL}$ & $0.0313 \mu \mathrm{g} / \mathrm{mL}$ & $0.5 \mu \mathrm{g} / \mathrm{mL}$ \\
6 & $0.125 \mu \mathrm{g} / \mathrm{mL}$ & $8 \mu \mathrm{g} / \mathrm{mL}$ & $0.0313 \mu \mathrm{g} / \mathrm{mL}$ & $0.5 \mu \mathrm{g} / \mathrm{mL}$ \\
7 & $0.125 \mu \mathrm{g} / \mathrm{mL}$ & $16 \mu \mathrm{g} / \mathrm{mL}$ & $0.25 \mu \mathrm{g} / \mathrm{mL}$ & $0.5 \mu \mathrm{g} / \mathrm{mL}$ \\
8 & $0.125 \mu \mathrm{g} / \mathrm{mL}$ & $32 \mu \mathrm{g} / \mathrm{mL}$ & $0.125 \mu \mathrm{g} / \mathrm{mL}$ & $1 \mu \mathrm{g} / \mathrm{mL}$ \\
9 & $0.125 \mu \mathrm{g} / \mathrm{mL}$ & $>64 \mu \mathrm{g} / \mathrm{mL}$ & $0.125 \mu \mathrm{g} / \mathrm{mL}$ & $1 \mu \mathrm{g} / \mathrm{mL}$ \\
10 & $0.25 \mu \mathrm{g} / \mathrm{mL}$ & $64 \mu \mathrm{g} / \mathrm{mL}$ & $0.125 \mu \mathrm{g} / \mathrm{mL}$ & $0.5 \mu \mathrm{g} / \mathrm{mL}$ \\
11 & $0.25 \mu \mathrm{g} / \mathrm{mL}$ & $>64 \mu \mathrm{g} / \mathrm{mL}$ & $0.0625 \mu \mathrm{g} / \mathrm{mL}$ & $1 \mu \mathrm{g} / \mathrm{mL}$ \\
12 & $0.5 \mu \mathrm{g} / \mathrm{mL}$ & $>64 \mu \mathrm{g} / \mathrm{mL}$ & $>0.5 \mu \mathrm{g} / \mathrm{mL}$ & $2 \mu \mathrm{g} / \mathrm{mL}$ \\
\hline
\end{tabular}

MIC: minimum inhibitory concentration. 


\section{DISCUSSION}

This study evaluated the classical laboratory methods to confirm the diagnosis of clinically suspected cases of feet onychomycosis. Similarly to the findings described by Souza et al. and Costa-Orlandi et al., a positive rate of around $60 \%$ was found, and most cases were clinically characterized as DLSO. ${ }^{14,15}$ These data are in agreement with literature reports that characterize DLSO as the most commonly observed clinical pattern..$^{16.17}$

Cases whose clinical diagnosis of onychomycosis was not confirmed by laboratory tests may indicate false-negative results due to irregular fungal distribution in the lesions or due to extensive keratinization, which makes it difficult to perform a proper collection of nail material and leads to absent or scarce fungal spores in the sample. ${ }^{18}$ In this context, Meireles et al. ${ }^{18}$ propose performing mycological tests in three consecutive samples collected at intervals from 2 to 5 days, which is proven to increase diagnostic accuracy.

On the other hand, some of these cases whose mycological tests were negative may have been clinically confounded with onychomycosis when they could actually represent nail changes caused by psoriasis, lichen planus, traumatic onychodystrophy and onycholysis, idiopathic onycholysis, nail tumors, and other conditions and changes that should always be included in the differential diagnosis of onychomycosis. ${ }^{11,13,19}$

The weak agreement between DME and culture observed in our investigation $(\mathrm{Kappa}<0.40)$ is lower than that described by Souza et al. (Kappa $=0.54$ ) and by Zanardi et al. (Kappa=0.63) and is related to differences in sensitivity between the two techniques., ${ }^{2,1420}$ This difference, which arises from the higher positivity detected in DME compared to culture methods, has been found both in our study and in those conducted by other authors and results from the fact that positive results are observed in culture methods only when the microorganism reproduces to form fungal colonies, which requires fungi to be viable. Conversely, fungal viability is not required for achieving positive results in DME, a test that allows visualizing parasite fungal structures even they are not viable. ${ }^{2,14}$ Cases of onychomycosis whose samples were positive for DME and negative for fungal culture may also be attributed to culture contamination by anemophilous microorganisms that hamper the identification of the real etiologic agent. ${ }^{20}$

Although mycological culture is less sensitive and capable of confirming a smaller number of cases of onychomycosis when compared to DME, it should be emphasized that it has higher specificity. ${ }^{2}$ Thus, both tests should always be performed for the etiologic diagnosis of onychomycosis, because DME allows observing only the vegetative structures of the fungus (parasitism) from the sample, but the reproductive structures required for fungal identification can only be visualized after the microorganism is isolated in culture medium.

Of the 27 cases whose mycological culture revealed fungal growth, 19 were caused by dermatophytes, and T. rubrum was considered the main etiologic agent, accounting for $89.4 \%$ of the cases of tinea unguium, which is in agreement with the literature showing that this species is the main cause of nail involvement, especially in terms of toenails. ${ }^{11,15,172.21-24}$

The rate of $5.1 \%$ of cases caused by yeasts is similar to that found by Lopes et al. ${ }^{9}$, who observed that yeasts were responsible for between 1.7 and 2.8\% of the cases of feet onychomycosis. Araújo et al..$^{25}$ and Martelozzo et al. ${ }^{20}$ also obtained similar results in their studies and observed that these agents were more frequently isolated in fingernails than in toenails $(26.1 \%$ and $37 \%$ in feet onychomycosis and $93.4 \%$ and $76 \%$ in hand onychomycosis respectively).

In our study, NDFFs accounted for 8.5\% (5/59) of the confirmed cases of onychomycosis and, similarly to what has been previously described, Fusarium sp. was the main causative agent. ${ }^{18,26}$ Considering that these microorganisms may be contaminant or colonize bodily areas with no clinical implication, they can only be considered the etiology of onychomycosis when their culture isolation is associated with the presence of tortuous hyaline hyphae in DME, which occurred in our study, or when the same NDFF is isolated from repeated samples collected at two or more different times and there is no growth of dermatophytes. ${ }^{2,26,27}$

Mean age of patients with confirmed onychomycosis was nearly 50 years, and there was a predominance of females, who accounted for $72.9 \%$ of the cases, but with no statistical difference. These data are in agreement with those of literature showing a frequency of onychomycosis ranging from $67 \%$ to $74 \%$ in females and higher frequency of disease in adults aged over 40 years. ${ }^{6,9,10,15}$ These findings are justified by differences in habits of hygiene and nail care, which are more related to females than to males, since fungal infection depends on factors related to the host. ${ }^{15}$

The trend of this disease to evolve and become chronic was evidenced in our study by the fact that nearly $50 \%$ of patients presented with lesions caused by onychodystrophy and had more than two nails affected by disease, $75 \%$ reported that the lesions had appeared more than 1 year before, and $44.1 \%$ presented with associated tinea pedis. ${ }^{25,6}$

More than a half of the total number of study patients reported previous use of antifungals $(61 \%)$, which shows the difficulty in treating onychomycosis 
and its high rates of recurrence, issues that may be attributed to different factors such as host circulatory disorders, nail hyperkeratosis (a condition that hinders drug penetration into the skin), drug bioavailability, advanced age, drug interactions, or inadequate treatments. ${ }^{3,422.24}$ It should be emphasized that inadequate treatments, caused either by high costs or complexity, involve lack of patient adherence to posology and/or to the recommended treatment period - which often leads to discontinuation of therapy -, and may result in the increase in fungal resistance to drugs. ${ }^{24}$

In this context, in vitro susceptibility tests of onychomycosis agents to the main antifungals used in the treatment of this infection have demonstrated the existence of strains with in vitro resistance to antifungals, as observed in our study, where $66.7 \%$ of isolates of T. rubrum showed high MIC values for fluconazole, $25 \%$ for itraconazole, and only one isolate for the four antifungals tested..$^{3,422,24}$ Similar values for fluconazole, itraconazole and terbinafine were described by Araújo et al. ${ }^{28}$ Susceptibility data against our 12 isolates of T. rubrum were also in agreement with other studies that point out to high MIC values for fluconazole and better response of terbinafine as an antifungal against dermatophytes. ${ }^{3,22,29}$
In line with the abovementioned findings, authors suggest that the most efficient antifungals for the systemic treatment of onychomycosis are usually terbinafine and itraconazole. Both substances are associated with better therapeutic results, shorter treatment time, longer remission time, and less side effects. ${ }^{30-32}$

\section{CONCLUSION}

Mycological tests allowed to confirm the diagnosis of onychomycosis in 59\% of patients with nail diseases suggestive of fungal infections. Significantly higher positivity rates were found in DME compared with culture, revealing weak agreement between the two tests. Additionally, high MICs for fluconazole were found against more than a half of clinical isolates of T. rubrum, while the other antifungals tested in this study (itraconazole, ciclopirox, and terbinafine) showed good in vitro activity against this etiologic agent. 


\section{REFERENCES}

1. Haneke E. Fungal infections of the nail. Semin Dermatol. 1991;10:41-53.

2. Zanardi D, Nunes DH, Pacheco AS, Tubone MQ, Souza Filho JJ. Evaluation of the diagnostic methods of onychomycosis. An Bras Dermatol. 2008;83:119-24.

3. Almeida LM, Souza EA, Bianchin DB, Svidzinski TI. In vitro response of cutaneous mycosis fungal agents to the most widely used systemic antifungals in dermatology. An Bras Dermatol. 2009;84:249-55.

4. Magagnin CM, Stopiglia CD, Vieira FJ, Heidrich D, Machado M, Vetoratto G, et al Antifungal susceptibility of dermatophytes isolated from patients with chronic renal failure. An Bras Dermatol. 2011;86:694-701

5. van der Schroeff JG, Cirkel PK, Crijns MB, Van Dijk TJ, Govaert FJ, Groeneweg DA, et al. A randomized treatment duration finding study of terbinafine in onychomycosis. Br J Dermatol. 1992;126:36-9.

6. Souza EAF, Mota VA, Almeida LMM, Rossi RM, Guilhermetti E, Svidzinski TIE. Frequency of onychomycoses caused by yeasts in Maringa, Parana, Brazil. An Bras Dermatol. 2007;82:151-6.

7. Scher RK. Onychomycosis is more than a cosmetic problem. $\mathrm{Br} \mathrm{J}$ Dermatol. 1994;130:15.

8. Lubeck DP. Measuring health-related quality of life in onychomycosis. J Am Acad Dermatol. 1998;38:S64-8.

9. Lopes J0, Alves SH, Mari CR, Oliveira LT, Brum LM, Westphalen JB, et al. A ten year survey of onychomycosis in the Central Region of the Rio Grande do Sul, Brazil. Rev Inst Med Trop Sao Paulo. 1999;41:147-9.

10. Araújo AJG, Souza MAJ, Bastos OM, Oliveira JC. Occurrence of onychomycosis among patients attended in dermatology offices in the city of Rio de Janeiro, Brazil. An Bras Dermatol. 2003:78:299-308.

11. William HC. The epidemiology of onychomycosis in Britain. $\mathrm{Br} J$ Dermatol. 1993:129:101-9.

12. Elewski BE. Onychomycosis: pathogenesis, diagnosis, and management. Clin Microbiol Rev. 1998;11:415-29.

13. Fillus Neto J, Tchornobay AM. How the nail clipping helps the dermatologist. An Bras Dermatol. 2009;84:173-6.

14. Souza PR, Vettorato G, Pinto GM, Duquia RP, Amaro TG, Almeira Junior HL, et al. Concordance between direct microscopy and fungical culture for the diagnostic of feet's onychomycosis. An Bras Dermatol. 2012;87:157-9.

15. Costa-Orlandi CB, Magalhães GM, Oliveira MB, Taylor EL, Marques CR, de ResendeStoianoff MA. Prevalence of Dermatomycosis in a Brazilian Tertiary Care Hospital. Mycopathologia. 2012;174:489-97.

16. Kaur R, Kashyap B, Bhalla P. Onychomycosis - epidemiology, diagnosis and management. Indian J Med Microbiol. 2008;26:108-16.

17. Sabadin CS, Benvegnú SA, da Fontoura MM, Saggin LM, Tomimori J, Fischman 0 . Onychomycosis and Tinea Pedis in Athletes from the State of Rio Grande Do Sul (Brazil): A Cross-Sectional Study. Mycopathologia. 2011;171:183-9.

18. Meireles TE, Rocha MF, Brilhante RS, Cordeiro Rde A, Sidrim JJ. Successive mycological nail tests for onychomycosis: a strategy to improve diagnosis efficiency. Braz J Infect Dis. 2008;12:333-7.

19. Rothmund G, Sattler EC, Kaestle R, Fischer C, Haas CJ, Starz H, et al. Confocal laser scanning microscopy as a new valuable tool in the diagnosis of onychomycosiscomparison of six diagnostic methods. Mycoses. 2013;56:47-55.

20. Martelozzo IC, Guilhermettil E, Svidzinski TIE. Ocorrência de onicomicose em Maringá, Estado do Paraná, Brasil. Acta Sci Health Sci. 2005; 27:176-81.

21. Siqueira ER, Ferreira JC, Maffei CML, Candido RC. Ocorrência de dermatófitos em amostras de unhas, pés e mãos coletadas de estudantes universitários. Rev Inst Med Trop. 2006;39:269-71.

22. Sarifakioglu $E$, Seckin $M$, Demirbilek, Can F. In vitro antifungal susceptibility patterns of dermatophyte strains causing tinea unguium. Clin Exp Dermatol. 2007;32:675-9.

23. Aghamirian MR, Ghiasian SA. Onychomycosis in Iran: Epidemiology, Causative Agents and Clinical Features. Nihon Ishinkin Gakkai Zasshi. 2010;51:23-9.

24. Peres NTA, Maranhão FCA, Rossi Antônio, Martinez-Rossi NM. Dermatophytes: hostpathogen interaction and antifungal resistance. An Bras Dermatol. 2010;85:657-67.

25. Araújo AJG, Souza MAJ, Bastos OM, Oliveira JC. Onychomycosis caused by emergent fungi: clinical analysis, diagnosis and revision. An Bras Dermatol 2003;78:445-55.

26. Gupta AK, Drummond-Main C, Cooper EA, Brintnell W, Piraccini BM, Tosti A. Systematic review of nondermatophyte mold onychomycosis: Diagnosis, clinical types, epidemiology, and treatment. J Am Acad Dermatol. 2012;66:494-502.
27. Gupta AK, Cooper EA, MacDonald P, Summerbell RC. Utility of inoculum counting (Walshe and English criteria) in clinical diagnosis of onychomycosis caused by nondermatophyte mold onychomycosis. J Clin Microbiol. 2001;39:2115-21.

28. Araújo CR, Miranda KC, Fernandes Ode F, Soares AJ, Silva Mdo R. In vitro susceptibility testing of dermatophytes isolated in Goiania, Brazil, against five antifungal agents by broth microdilution method. Rev Inst Med Trop Sao Paulo. 2009;51:9-12.

29. Nweze El, Ogbonna CC, Okafor Jl. In vitro susceptibility testing of dermatophytes isolated from pediatric cases in Nigeria against five antifungals. Rev Inst Med Trop Sao Paulo. 2007;49:293-5.

30. Elewski BE, Hay RJ. Update on the management of onychomycosis: highlights of the Third Annual International Summit on Cutaneous Antifungal Therapy. Clin Infect Dis. 1996;23:305-13.

31. Sigurgeirsson B. Prognostic factors for cure following treatment of Onychomycosis. J Eur Acad Dermatol Venereol. 2010;24:679-84

32. Graham LVD, Elewski BE. Recent updates in oral terbinafine: its use in onychomycosis and tinea capitis in the US. Mycoses. 2011;54:e679-85.

MAILING ADDRESS:
Gabriel Baracy Klafke
Rua Visconde de Paranaguá 102 - Centro
96203-900 - Rio Grande - RS
Brazil
E-mail: gabrielklafke@yahoo.com.br

MAILING ADDRESS:

Gabriel Baracy Klafke

Rua Visconde de Paranaguá 102 - Centro

Brazil

How to cite this article: Azambuja CVA, Pimmel LA, Klafke GB, Xavier MO. Onychomycosis: clinical, mycological and in vitro susceptibility testing of isolates of Trichophyton rubrum. An Bras Dermatol. 2014;89(4):581-6. 